\title{
Challenges Faced by Hospital Pharmacists in Low- Income Countries Before COVID-19 Vaccine Roll- Out: Handling Approaches and Implications for Future Pandemic Roles
}

\author{
(1) Rajeev SHRESTHA ${ }^{1 *}$, (1) Sunil SHRESTHA ${ }^{2}$, (1) Binaya SAPKOTA ${ }^{3}$, (1) Saval KHANAL ${ }^{4}$, (1) Bhuvan KC ${ }^{2}$ \\ 1Lamjung District Community Hospital, Department of Pharmacy, Lamjung, Nepal \\ 2Monash University Malaysia, School of Pharmacy, Selangor, Malaysia \\ 3 Nobel College, Department of Pharmaceutical Sciences, Kathmandu, Nepal \\ ${ }^{4}$ University of Warwick, Warwick Medical School, Department of Health Sciences, Coventry, United Kingdom
}

\begin{abstract}
Coronavirus disease-2019 (COVID-19) is one of the greatest pandemics of modern times. More than one hundred eleven million global deaths have already been associated with COVID-19. The incidence of COVID-19 as well as morbidity and mortality due to COVID-19 have increased in lowincome countries (LICs). COVID-19 has further weakened health systems in LICs, that are already distressed by inadequate funding, lack of human resources, and poor infrastructure and service delivery. Despite the resource crunch, hospital LICs have been instrumental in treating COVID-19 patients. Pharmacists working in hospitals play an indispensable role in providing pharmaceutical services for infection prevention and control. This study discusses the contribution of hospital pharmacists and the challenges faced by them for treating COVID-19 patients in LICs before the COVID-19 vaccine roll-out.
\end{abstract}

Key words: COVID-19, hospital pharmacy, hospital pharmacist, low-income countries, pharmacy service, pharmacist

\section{INTRODUCTION}

Coronavirus disease-2019 (COVID-19) is a current ongoing global threat. It is one of the fatal pandemics in the history of humankind. As per the World Health Organization (WHO), as of March 3, 2021, there were 114,140,104 confirmed cases and 2,535,520 deaths globally. Similarly, 828,461 confirmed cases and 14,749 deaths in low-income countries (LICs). Among 31 LICs, coronavirus deaths are found in 30 countries, and $83.87 \%$ of countries had community transmission, too.' LICs are those countries that have a very low, i.e. $\$ 1,035$ or less gross national income in 2019. ${ }^{2}$

Vaccines against COVID-19 have been developed and rolled over in many countries. Before that, the non-pharmacological interventions to contain the virus, such as social distancing and personal hygiene, were only mechanisms that prevent the transmission. The LICs, often have a huge population concentrated in a few cities, living in overcrowded conditions. ${ }^{3}$ It is difficult to maintain social distancing for people. Furthermore, people did not have access to adequate hand sanitizer and other protective measures required for preventing transmission. ${ }^{3}$ Healthcare systems LICs were traditionally developed to deliver basic health services and treatment of some life-threatening infective diseases. These systems are already overstretched and struggling to cope with the increasing burden of noncommunicable diseases. ${ }^{4}$ During this transition phase, the emergence of COVID-19 had presented significant challenges to LICs where the accessibility of quality and affordable health services is poor. ${ }^{5,6}$ 
All healthcare professionals and health institutions must strengthen themselves against the COVID-19 or any pandemic situation. Like other healthcare professionals, hospital pharmacists also play a significant role in preventing and controlling pandemic. The International Pharmaceutical Federation (FIP) has developed guidelines for hospital pharmacists considering their imperative value during the disaster and pandemic control.7,8 Various studies have identified the importance of pharmacists' roles in providing pharmaceutical care and services during infection control and managing disaster complications. 9.10 Pharmacists are the third largest healthcare professionals in the world after physicians and nurses, ${ }^{10}$ but they are still struggling to prove their value in the healthcare systems of LICs. ${ }^{11}$ The current review discusses the hospital pharmacists' potential contributions in the management of disasters and the challenges they faced in LICs. The discussion is based on the situation before the development of COVID-19 vaccines. The reflection will help different stakeholders to understand how essential pharmacists are to healthcare delivery during pandemics and how they can effectively use hospital pharmacists during any future pandemics.

\section{METHODS}

We performed a narrative review of the existing literature known to the authors. The literature was searched in PubMed, MEDLINE, ScienceDirect and Google Scholar from its inception up to and including May 2020. Key search terms included were "pharmacist," “COVID-19," “low-income countries," "pharmacy," "hospital" and "developing countries." Along with this, various synonyms or combinations of these terms have been used. The authors viz. R.S., S.S. are working as the hospital and clinical pharmacists in the hospital. S.K., B.S. and B.K.C. are in academia, but had experience working as a pharmacists in the past. We have themed potential activities and challenges into different headings to improve readability. The potential role of hospital pharmacists is mainly based on FIP and Nepal (a lic) guidelines for managing COVID-19. The main features of both guidelines are presented in Table 1.

\section{RESULTS}

Potential role of hospital pharmacists in the management of COVID-19 and pandemics

The healthcare systems in LICs differs from one country to another. Therefore, it would be difficult to generalize what exactly a hospital pharmacist can provide in general. However, we propose these activities (Figure 1), which may be possible in many LIC jurisdiction under the existing legal and professional framework. These are the recommended role; some of these might not be legal in some countries. The role presented in Figure 1 is described below individually in subsequent sections.

\section{Pharmaceutical management}

Access to adequate, qualitative, and affordable essential medicines is challenging in LICs. ${ }^{13}$ Medicine accessibility has been a problem during COVID-19 because of the disruption in manufacture, distribution and logistics. Hospital pharmacists played an important role in this situation via handling of medicine logistics via appropriate forecasting, stocking, quality maintenance, and optimum usage of resources.

In close consultation with clinicians, pharmacists can develop a strategy for using available therapeutic alternatives, such as converting the oral dosage form to intravenous, selecting equivalent alternative medicine to tackle drug shortage.14,15 Hospital pharmacies use detailed information about their regular patients through electronic billing systems or other recordkeeping forms. Therefore, they can estimate and transfer the required medications of their patients appropriately. Pandemic has broadly taught about keeping patient's medication record practice. It must be started if many hospital pharmacies do not have a system of keeping patient's medication record. Medication records are essential not only for better logistics and distribution but also for measuring patient's adherence to medication therapy and effective management of therapy. ${ }^{16,17}$

\section{Drug information service}

Access to reliable information is crucial to the public and healthcare professionals during a pandemic. Fake or incomplete information is dreadful. It can even cause severe accidents, when the public figure personnel become a medium of rumor.

Similarly, more than 700 people in Iran died in about two months after injecting methanol following the manipulation of information raised by another misinformation by an influential global leader regarding the possibility of injecting disinfectant to cure COVID-19. ${ }^{18}$ Therefore, the correct information should be transmitted to both the general public and healthcare professionals. Pharmacists have a fundamental professional responsibility to continuously evaluate the existing literature and make health professionals and public awareness of the pandemic and its medicinal management by providing accurate, unbiased information. ${ }^{19-21}$ Currently, several medicines and vaccines are under trial for COVID-19 treatment. Pharmacists can be a part of the clinical trial team to manage and provide information on medicine or vaccine under trial. The pharmacist can also use various informative pictures, pamphlets, and information sheets to make patient aware, when they visit hospitals.

\section{Patient screening and triaging}

Social distancing is one of the most crucial approaches to pandemic control. Consequently, the initial screening of patients visiting the hospital could save unwanted contact with the hospital staff and patients. The pharmacy department and hospital pharmacists can play a significant role in initial screening and triage. The pharmacist can offer the initial evaluation of the patient. They can either recommend patients for clinician consultation or send them back home with OTC medications or non-pharmacological counseling in case of minor conditions. The pharmacist can also perform rapid diagnostic tests of suspected patients segregate immediately. These approaches could save unwanted clinician workload 
Table 1. Guidelines for COVID-19 management by the hospital pharmacy and the pharmacists (FIP and Nepal) ${ }^{7,12}$

\begin{tabular}{ll} 
Organization & Features of the guidelines \\
\hline & - Ensuring healthy inventory management of pharmaceutical products (both medicines and medical devices) and a \\
& good supply system \\
International & - Liaising with other healthcare professionals in providing patient care and support \\
Pharmaceutical & - Promoting infection control mechanisms in hospitals \\
Federation (FIP) & - Promoting health education and counseling \\
& - Ensuring responsible and proper use of the pharmaceutical products and personal protective equipment supplied. \\
& Providing pharmacovigilance services and monitoring treatment outcomes \\
\hline & - Ensuring storage and supply of essential medicinal and surgical products, including mask, a thermometer, goggles \\
Nepal Pharmaceutical & - Co-ordinating with other healthcare professionals in patient care \\
Association & - Raising public awareness regarding COVID-19 prevention and control \\
& - Monitoring treatment outcomes and pharmacovigilance \\
& - Ensuring an inventory of medicine in both inpatients and outpatients with COVID-19 pandemic cases
\end{tabular}

COVID-19: Coronavirus disease-2019, FIP: International Pharmaceutical Federation

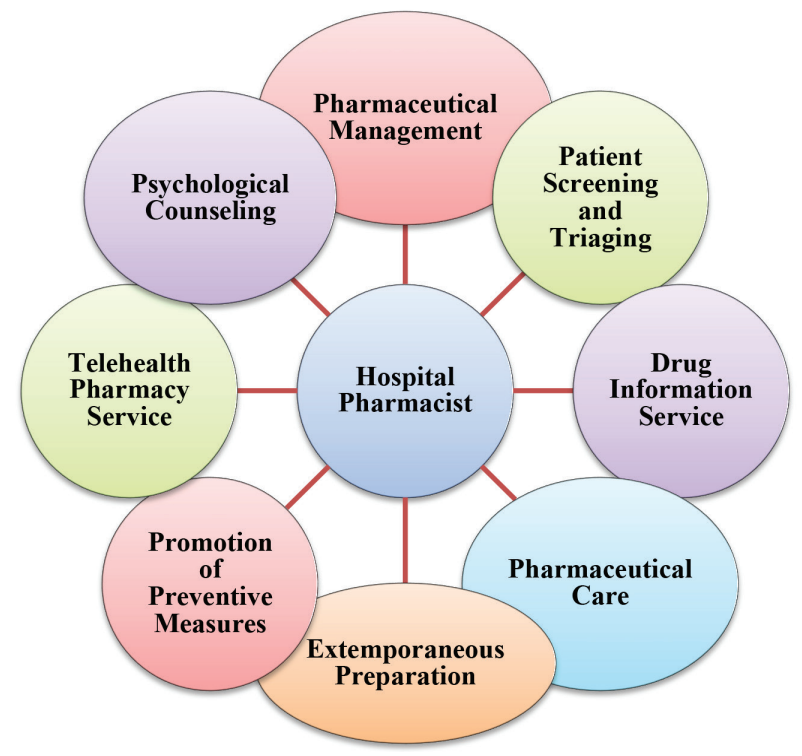

Figure 1. The role hospital pharmacists can play in COVID-19 and pandemic control in LICS

and prevent infection transmission possibility in the pandemic. The FIP has also made specific guidelines for pharmacists in disaster and pandemic situations. ${ }^{7,8}$ The guidelines instruct pharmacists to initial screening patients to provide first aid, triage, screening, and treating minor ailments. ${ }^{7,8}$ In some developed countries, pharmacists have adopted that role earlier, too. ${ }^{22}$ Therefore, LICs should also attempt to prepare, equip and use the pharmacy workforce optimally in disaster situations.

\section{Pharmaceutical care}

China implemented pharmaceutical care programs as substantial service in COVID-19 as it was reported to have a significant impact on patient outcomes. ${ }^{23-25}$ Pharmaceutical care is much needed care for the treatment and management of COVID-19 patients, especially for elderly patients and patients with chronic diseases as they are at a higher risk of developing drug interactions and adverse effects as well as their use of complex medication regimens. ${ }^{26,27}$ For instance, chloroquine, azithromycin, and hydroxychloroquine can cause
QT prolongation and the administration of these medicines to patients already suffering from cardiovascular conditions can make them worse. ${ }^{28}$ Therefore, there was a need for close monitoring of patient medication status along with therapeutic outcomes. Hospital pharmacists should monitor and evaluate the medication dose, administration, drug interaction, and adverse effects to plan an appropriate medication formulary and medicine regimen in collaboration with other healthcare professionals. ${ }^{26,29,30}$ However, these clinical roles were not much emphasized in the guidelines made by LICs such as Nepal. $^{12}$

Along with that, pharmacists have a responsibility to provide information on medication outcomes, assess polypharmacy issues and monitor the medication compliance of patients. Patients might not come for regular follow up their medical condition and require self-medication because of pandemic fears and movement control order and such restrictive provisions. Therefore, pharmacists must proactively identify these patients and get regular updates about their clinical condition and provide proper counseling and refer them to hospitals if needed.

\section{Promotion of preventive measures}

In many countries, community pharmacies were closed because of COVID-19; and the hospital pharmacies served as a primary source to get medicine and precautionary material like "masks" and "hand sanitizers" to the public. Therefore, hospital pharmacists are the most accessible and responsible health professionals in providing pharmacy and preventive and promotive healthcare services such as an aseptic way of using the mask, hand washing, social distance values, isolated coughing, sneezing, required in COVID-19 prevention (12.35)., ${ }^{7,31}$ The study has previously shown a significant change in public health in controlling unhealthy behavior and promoting disease control, prevention, and drug abuse management through pharmacist involvement. ${ }^{24,32}$

\section{Extemporaneous preparation}

Healthcare-associated infections result in complications and even death. ${ }^{33}$ Simultaneously, simple hand hygiene can prevent diseases. ${ }^{34}$ As pharmacists are trained to conduct 
extemporaneous dispensing, pharmacist can prepare hand sanitizers, disinfectant liquids, etc., for hospitals' internal use and the community at the time of medical goods scarcity due to disaster. There have been multiple reports about pharmacists preparing such products and contributing to society to fight against COVID-19 in this exceptional circumstance..$^{35}$

\section{Telehealth pharmacy services (TPS)}

Access to pharmacy services was challenging during the pandemic, when people were not allowed to leave their home. Approaching pharmacy services by using telecommunication technology can solve that challenge. Continuous pharmaceutical care is prominent, particularly for chronic disease patients who are at higher risk of infection and have already undertaken multiple medicines. Thus, TPS was a suitable way to reach the patient. TPS can serve people living in far-off places, selfquarantined and people unable to visit a hospital pharmacy using email, phone call, text message, or social media. ${ }^{36,37}$ Hospital pharmacists can collect patient's medicine and disease information and supply medicine to a respective patients with appropriate labeling and counsel on medicine administration through phone calls or any other online media. ${ }^{36}$ Furthermore, pharmacists can advise patients on self-monitoring of medicine effectiveness and self-management of minor ailments and whether to continue their medicine or visit a center centre on a phone call or at the doorstep, while delivering medications. ${ }^{24,38}$ Good access to the internet and telecommunication is highly essential to providing TPS, which may be problematic in many villages of LICs.

Many developed countries have been using telepharmacy services. ${ }^{37}$ In response to the pandemic, Australia enhanced its existing telepharmacy practices, ${ }^{39}$ and China also emphasized the online pharmacy consultation for COVID-19.40 Although online consultation and medicine delivery are difficult in LICs, the hospital pharmacist must attempt to start this approach in coordination with their hospital administration, at least in a disaster situation.

\section{Psychological counseling}

Because of the pandemic and lockdown, people could not move and were forced to confine themselves inside their home. The changing daily routine and the thought of death, pandemic, and growing disease progression affect people's thinking patterns, leading to anxiety, panic, and depression, to psychological problems. ${ }^{41,42}$ Psychological problems can be more pressing in mentally ill patients, low-socioeconomic groups, and cardiovascular diseases like chronic illness patients. ${ }^{43,44}$ Therefore, pharmacists should monitor the patient's emotional states and encourage them to perform stress-relieving activities.

\section{Professional challenges of pharmacists and possible solutions in disaster management}

Although we proposed some roles, they do not come without challenges. We have identified six challenges related to these roles and presented them in Figure 2 . These problems and potential solutions are described in the different subheadings in this section of this manuscript.

\begin{tabular}{|c|c|}
\hline Shortage of safety measures & $\begin{array}{l}\text { - Promoting local entreprenurship } \\
\text { - Extempraneous preparation of hand sanitizer } \\
\text { - Telehealth pharmacy services }\end{array}$ \\
\hline $\begin{array}{l}\text { Difficulty in adequate } \\
\text { medication management }\end{array}$ & $\begin{array}{l}\text { - Need based minimal medicine prescribing } \\
\text { - Medicine substitution }\end{array}$ \\
\hline $\begin{array}{l}\text { Shortness of pharmacy } \\
\text { manpower }\end{array}$ & $\begin{array}{l}\text { - Utilizing pharmacy students and medical } \\
\text { personnel } \\
\text { - Long term planning on qualified pharmacy } \\
\text { persoonel development }\end{array}$ \\
\hline $\begin{array}{l}\text { Non-existent or less priority to } \\
\text { pharmaceutical care }\end{array}$ & $\begin{array}{l}\text { - Promotion and utilization of pharmacy personnel } \\
\text { in pharmaceutical care }\end{array}$ \\
\hline $\begin{array}{l}\text { Poor security to health care } \\
\text { professionals }\end{array}$ & $\begin{array}{l}\text { - Assure basic need and health } \\
\text { - Site allocation and Esnure the safety of work } \\
\text { place } \\
\text { - Appropriating training }\end{array}$ \\
\hline Non-favourable legislation & $\begin{array}{l}\text { - Formulation of appropriate guideline for } \\
\text { emergency prepared } \\
\text { - Promotion of appropriate education to developed } \\
\text { skillful pharmacy personnel }\end{array}$ \\
\hline
\end{tabular}

Figure 2. Challenges and solutions

\section{Shortage of safety measures}

As per the WHO, the appropriate protective materials like surgical masks, eye protection and face shield, long-sleeved gowns, and gloves are the basic needs to work in a health institution during COVID pandemics. ${ }^{31}$ Hospital pharmacists were at a high risk of getting infected, and they could be a medium of transmission as they were in close contact with patients visiting the hospitals. ${ }^{7}$ However, the availability of precautionary safety materials to healthcare professionals, including pharmacists, has become challenging in LICs where there are no manufacturing companies for these protective supplies. ${ }^{31,45,46}$ Therefore, LICs should promote local entrepreneurs to produce personal protective equipment and mask-like protective measures without relying on imports from outside. Hospital pharmacists can contribute in this regard by extemporaneous compounding hand sanitizer gels, sprays, etc.

\section{Difficulty in adequate medication management}

Many LICs are not self-reliant and vastly depend on the import of medication from foreign countries. Thus, due to the possibility of a drug shortage or delayed supply chain system due to travel restrictions during a pandemic, adequate and timely access to essential medicine in healthcare settings can be challenging in many countries. ${ }^{45}$ The situation may become more difficult for people with a chronic condition for whom missing a few doses of medication can be life-threatening. The hospital pharmacist had a responsibility to update the prescribers on available medicines and their inventory. This helped prescribers make appropriate prescribing decisions like prescribing only to the needed patients in minimum quantities to reduce the unnecessary wastage of medicine and prevent the medicine shortage. It also helped them decide whether to prescribe multiple refills to one patient or make a single refill to multiple patients. The appropriate quantification and stocking of medication-related to COVID-19, such as remdesivir and chloroquine, were essential based on the clinical practice. However, it came down to pharmacists' expertise to forecast the usage because overstocking may cause a shortage of these medications for those who require them regularly. ${ }^{47}$

Furthermore, there might have been a problematic situation related to brand prescriptions, when patients rely on a particular 
hospital for their continued medication. Brand prescribing is very common in LICs and a refill of a particular brand or searching for a particular brand for the patient is very tough, when there is a shortage due to the lockdown. ${ }^{48}$ Also, there may come to some circumstances in disasters or pandemics, where the patient may not find a generic substitution and clinician consultation. Furthermore, pharmacists could only be an option to manage the patients. Therefore, the pharmacists should be allowed to substitute medicine for therapeutically equivalent alternatives in consultation with the prescribers, if they are accessible or without consultation if the prescribers are inaccessible to consult in a disaster situation. The FIP in 2016 made a guidelines focusing on pharmacy personnel's role in the disaster where pharmacists can also do some emergency prescribing if needed. That should be strongly taken into consideration by the responsible bodies in LICs. At least, pharmacists should be prepared to prescribe the essential medications during the pandemic and other similar disaster. ${ }^{8}$ However, it was not seen in the guidelines made by LICs, ${ }^{12}$ which are quite hard to implement for LICs. Convincing with the local hospital administration and legal body would help solve this problem to some extent.

\section{Shortage of pharmacy human resources}

Pharmacists have been importing a significant role in providing pharmacy services in pandemic prevention and control. ${ }^{49}$ COVID-19 has already caused the death of many health professionals in developed countries..$^{50}$ The situation could be even more devastating for LICs, where there is already a shortage of pharmacy human resources. ${ }^{51,52}$ The death, hospitalization or isolation of limited human resources would increase the workload. Eventually, it hampered the pharmaceutical services of patients. Therefore, the LICs should work proactively in developing and equipping sufficient human resources to defeat disaster challenges. Pharmacy students and non-pharmacy medical personnel can be used through immediate short-term training to cope with the current pharmacy workforce shortage in providing pharmaceutical services. Also, the pharmacy services can be provided to a large group by small human resources through the TPS approach. ${ }^{36}$

\section{Non-existent or less priority to pharmaceutical care}

The pharmacy personnel in LICs are primarily focused on the product approach (procurement, inventory, and dispensing). Although pharmaceutical care has been determined as a vital aspect of treatment, the environment of providing pharmaceutical services and access to quality workforce still lacks in LICs. $31,40,51,53$ LICs should learn the importance of pharmaceutical care or the clinical service of pharmacy personnel. They must use the available pharmacy personnel in providing pharmaceutical care, at least, in this disaster. Eventually, LICS should make appropriate policies and guidelines to promote the pharmacist in a clinical role in the healthcare system.

Poor security to healthcare professionals

Healthcare professionals also need motivation and security during a disaster. Taking personal care of oneself, along with continuous working for others' health, was relatively complicated. Healthcare personnel, including pharmacists, require appropriate motivation and support from the government and respective health centers. Pharmacists have been greatly appreciated even financially in developed countries like New Zealand for their remarkable contribution during pandemics. ${ }^{25}$ The respective health institutions and governments of LICS should also learn from them and provide essential facilities such as food, lodging for them and their families during this disaster if they could not reward them as high-income countries did.

Similarly, protecting and preventing infection transmission to healthcare personnel is supremely essential because healthcare providers themselves can transmit others while serving. Previously, up to $10 \%$ of COVID cases in China and up to $9 \%$ in Italy were healthcare personnel..$^{50}$ Infection of healthcare personnel not only increases patient numbers but also reduces persons to care for patients. Therefore, stringent health approaches need to be adopted to prevent infection transmission. China made a strict guidelines for cleansing, disinfecting, and controlling human movements to prevent infection transmission. ${ }^{40}$ Learning from them, LICs can create separate allocated places for COVID management, prepare disinfection guidelines and make designated sites for health personnel involved in COVID management.

Along with that, healthcare professionals, including hospital pharmacists, need to be aware and trained in following the safety procedures of work to prevent being infection and being a source of infection transmission. ${ }^{50}$ The concerned government and hospital administrative body should provide appropriate training to ensure healthcare providers' safety, including hospital pharmacist.

\section{Non-favorable legislation}

LICs suffer from a lack of appropriate pharmacy education, skilled and qualified personnel, and professional guidelines for effective professional functioning. ${ }^{53,54}$ Though similar professionals have significantly impacted the health sector in developed countries, a pharmacist suffers due to the deficient role from the concerned authority in LICs. ${ }^{53,54}$ Unprepared pharmacy professionals cannot play a significant role in emergencies and disaster situations. The recent earthquake disaster in Nepal taught much about preparing pharmacy services for disaster management in LICs. ${ }^{55}$ Many studies have already talked about the significant contributions pharmacists have made in pandemic and emergency disasters; therefore, along with the appropriate policy, pre-qualifying them through quality education and skill is the only necessity in LICs to defeat the disaster. ${ }^{49,56,57}$ Therefore, the LICs, where the pharmacists have not been adequately used to provide pharmaceutical services, should learn from the current COVID-19 pandemic and equip the pharmacy workforce to manage such possible future disasters through the appropriate formulation of guidelines and emergency training preparedness. Additionally, LICs or hospitals themselves can make separate guidelines for disaster situations by using FIP guidelines on responding to disasters for pharmacy personnel as a reference. ${ }^{8}$ 


\section{CONCLUSION}

The growing cases of COVID-19 have created significant challenges to the healthcare system and healthcare professionals of LICs. During COVID-19, hospital pharmacists were responsible for ensuring appropriate therapy outcomes, medication management, health promotion, pharmaceutical care of patients, and infection transmission prevention. The study recommends enhancing the hospital pharmacists' professional role in disaster and management for COVID-19 and other such disasters in the future.

\section{ACKNOWLEDGMENTS}

The authors want to thank Mrs. Nita Shrestha (Nepal Health Research and Innovation Foundation), Mr. Mandip Pokharel (Vennue Foundation) and Mr. Pankaj Vaidya (Nepal Cancer Hospital and Research Center) for their valuable suggestions and comments while developing the concept and overall writing.

\section{Ethics}

Peer-review: Externally peer-reviewed.

\section{Authorship Contributions}

Concept: R.S., S.S., Design: R.S., Data Collection or Processing: R.S., Analysis or Interpretation: R.S., S.S., B.S., B.K., S.K., Literature Search: R.S., Writing: R.S.

Conflict of Interest: No conflict of interest was declared by the authors.

Financial Disclosure: The authors declared that this study received no financial support.

\section{REFERENCES}

1. World Health Organization. WHO coronavirus disease (COVID-19) Dashboard. Published 2020. https://covid19.who.int/table

2. World Bank. World Bank Country and Lending Groups. Accessed February 25,2021. https://datahelpdesk.worldbank.org/knowledgebase/ articles/906519-world-bank-country-and-lending-groups

3. WHO/UNICEF. Water, sanitation and hygiene in health care facilities: status in low- and middle-income countries and way forward. Published online 2019:1-52. https://apps.who. int/iris/bitstream/handle/10665/154588/9789241508476_eng. pdf;jsessionid=8BB20D0F383BB2585E35A2CEA1EF1457? ?sequence $=1$

4. Hajat C, Stein E. The global burden of multiple chronic conditions: a narrative review. Prev Med Rep. 2018;12:284-293.

5. McGregor S, Henderson KJ, Kaldor JM. How are health research priorities set in low and middle income countries? A systematic review of published reports. PLoS One. 2014;9:e108787.

6. Agampodi TC, Agampodi SB, Glozier N, Siribaddana S. Measurement of social capital in relation to health in low and middle income countries (LMIC): a systematic review. Soc Sci Med. 2015;128:95-104.

7. International Pharmaceutical Federation (FIP). COVID-19: Guidelines for Pharmacists and the Primary Workforce; 2020. Accessed May 7, 2020. https://www.fip.org/files/content/priority-areas/coronavirus/COVID19-Guidelines-for-pharmacists-and-the-pharmacy-workforce.pdf

8. International Pharmaceutical Federation (FIP). Responding to disasters: Guidelines for Pharmacy 2016. Published online 2016:46. http://fip.org/
files/fip/publications/2016-07-Responding-to-disasters-Guideline.pdf

9. Watson KE, Singleton JA, Tippett V, Nissen LM. Defining pharmacists' roles in disasters: a Delphi study. PLoS One. 2019;14:e0227132.

10. Menighan TE. Pharmacists have major role in emergency response. Pharm Today. 2016;22:8.

11. Ranjit E. Pharmacy practice in Nepal. Can J Hosp Pharm. 2016;69:493500.

12. Association NP. Covid-19: Guideline for pharmacists and pharmacy assistant. Accessed April 28, 2020. https://www.fip.org/files/content/ priority-areas/coronavirus/mo-resources/NEPAL_Final_Guideline_ COVID.pdf

13. Ozawa S, Shankar R, Leopold C, Orubu S. Access to medicines through health systems in low-and middle-income countries. Health Policy Plan. 2019;34(Suppl 3):iii1-iii3.

14. Dalton K, Byrne S. Role of the pharmacist in reducing healthcare costs: current insights. Integr Pharm Res Pract. 2017;6:37-46.

15. AlRuthia YS, AlKofide H, AlAjmi R, Balkhi B, Alghamdi A, AlNasser A, Alayed A, Alshammari M, Alsuhaibani D, Alathbah A. Drug shortages in large hospitals in Riyadh: a cross-sectional study. Ann Saudi Med. 2017; 37:375-385.

16. Lam WY, Fresco P. Medication adherence measures: an overview. Biomed Res Int. 2015;2015:217047.

17. Barnsteiner JH. Chapter 38. Medication reconciliation. In: Hughes RG, ed. Patient Safety and Quality - An Evidence-Based Handbook for Nurses. 2008. https://www.ncbi.nlm.nih.gov/books/NBK2648/

18. Aljazeera. Iran: Over 700 Dead after drinking alcohol to cure coronavirus. www.aljazeera.com/news/2020/04/iran-700-dead-drinking-alcoholcure-coronavirus-200427163529629.html

19. Ghaibi S, Ipema H, Gabay M; American Society of Health System Pharmacists. ASHP guidelines on the pharmacist's role in providing drug information. Am J Health Syst Pharm. 2015;72:573-577.

20. Shrestha S, Khatiwada AP, Gyawali S, Shankar PR, Palaian S. Overview, challenges and future prospects of drug information services in Nepal: a reflective commentary. J Multidiscip Healthc. 2020;13:287-295.

21. World Health Organization. Coronavirus disease (COVID-19) advice for the public: mythbusters. https://www.who.int/emergencies/diseases/ novel-coronavirus-2019/advice-for-public/myth-busters

22. Epp DA, Tanno Y, Brown A, Brown B. Pharmacists' reactions to natural disasters: from Japan to Canada. Can Pharm J (Ott). 2016;149:204-215.

23. Song Z, Hu Y, Zheng S, Yang L, Zhao R. Hospital pharmacists' pharmaceutical care for hospitalized patients with COVID-19: recommendations and guidance from clinical experience. Res Social Adm Pharm. 2021;17:2027-2031.

24. Zheng SQ, Yang L, Zhou PX, Li HB, Liu F, Zhao RS. Recommendations and guidance for providing pharmaceutical care services during COVID-19 pandemic: a China perspective. Res Social Adm Pharm. 2021;17:1819-1824.

25. Bukhari N, Rasheed H, Nayyer B, Babar ZU. Pharmacists at the frontline beating the COVID-19 pandemic. J Pharm Policy Pract. 2020;13:8.

26. Shrestha S, Shrestha S, Khanal S. Polypharmacy in elderly cancer patients: challenges and the way clinical pharmacists can contribute in resource-limited settings. Aging Med (Milton). 2019;2:42-49.

27. Kurt M, Akdeniz M, Kavukcu E. Assessment of comorbidity and use of prescription and nonprescription drugs in patients above 65 years attending family medicine outpatient clinics. Gerontol Geriatr Med. 2019;5:2333721419874274. 
28. Saleh M, Gabriels J, Chang D, Soo Kim B, Mansoor A, Mahmood E, Makker P, Ismail H, Goldner B, Willner J, Beldner S, Mitra R, John R, Chinitz J, Skipitaris N, Mountantonakis S, Epstein LM. Effect of chloroquine, hydroxychloroquine, and azithromycin on the corrected QT interval in patients with SARS-CoV-2 infection. Circ Arrhythm Electrophysiol. 2020;13:e008662.

29. Elden NM, Ismail A. The Importance of medication errors reporting in improving the quality of clinical care services. Glob J Health Sci. 2016;8:54510.

30. Velo GP, Minuz P. Medication errors: prescribing faults and prescription errors. Br J Clin Pharmacol. 2009;67:624-628.

31. Al-Quteimat OM MSc, BCOP, Amer AM RPh, MSc. SARS-CoV-2 outbreak: how can pharmacists help? Res Social Adm Pharm. 2021;17:480-482.

32. Agomo CO. The role of community pharmacists in public health: a scoping review of the literature. J Pharm Heal Serv Res. 2012;3:25-33.

33. Haque M, Sartelli M, McKimm J, Abu Bakar M. Health care-associated infections - an overview. Infect Drug Resist. 2018;11:2321-2333.

34. Mathur P. Hand hygiene: back to the basics of infection control. Indian J Med Res. 2011;134:611-620.

35. Di-Falco E, Bourbon J, Sbaffe I, Kaiser J. Preparation of alcohol-based handrub in COVID-19 alsatian cluster. Pharm Technol Hosp Pharm. 2020. doi:10.1515/pthp-2020-0004.

36. Poudel A, Nissen LM. Telepharmacy: a pharmacist's perspective on the clinical benefits and challenges. Integr Pharm Res Pract. 2016;5:75-82. Erratum in: Integr Pharm Res Pract. 2016;5:83.

37. Le T, Toscani M, Colaizzi J. Telepharmacy: a new paradigm for our profession. J Pharm Pract. 2020;33:176-182.

38. Council on Credentialing in Pharmacy, Albanese NP, Rouse MJ. Scope of contemporary pharmacy practice: roles, responsibilities, and functions of pharmacists and pharmacy technicians. J Am Pharm Assoc (2003). 2010;50:35-69.

39. Department of Health AG. Fact sheet national health plan a guide for prescribers; 2020.

40. Association CP. Coronavirus 2019-NCoV infection: expert consensus on guidance and prevention strategies for hospital pharmacists and the pharmacy workforce (1 ${ }^{\text {st }}$ edition). First; 2020. Accessed April 24, 2020. https://www.fip.org/files/content/priority-areas/coronavirus/ CPA-CORONAVIRUS-2019-nCoV-Expert-Consensus-on-Guidanceand-Prevention.pdf

41. Holmes EA, O'Connor RC, Perry VH, Tracey I, Wessely S, Arseneault L, Ballard C, Christensen H, Cohen Silver R, Everall I, Ford T, John A, Kabir T, King K, Madan I, Michie S, Przybylski AK, Shafran R, Sweeney A, Worthman CM, Yardley L, Cowan K, Cope C, Hotopf M, Bullmore E. Multidisciplinary research priorities for the COVID-19 pandemic: a call for action for mental health science. Lancet Psychiatry. 2020;7:547-560.

42. Xiang YT, Yang Y, Li W, Zhang L, Zhang Q, Cheung T, Ng CH. Timely mental health care for the 2019 novel coronavirus outbreak is urgently needed. Lancet Psychiatry. 2020;7:228-229.
43. Mokdad AH, Mensah GA, Posner SF, Reed E, Simoes EJ, Engelgau MM; Chronic Diseases and Vulnerable Populations in Natural Disasters Working Group. When chronic conditions become acute: prevention and control of chronic diseases and adverse health outcomes during natural disasters. Prev Chronic Dis. 2005.

44. Dimsdale JE. Psychological stress and cardiovascular disease. J Am Coll Cardiol. 2008;51:1237-1246.

45. Kretchy IA, Asiedu-Danso M, Kretchy JP. Medication management and adherence during the COVID-19 pandemic: perspectives and experiences from low-and middle-income countries. Res Soc Adm Pharm. 2021;17:2023-2026.

46. Bong $\mathrm{CL}$, Brasher $\mathrm{C}$, Chikumba E, McDougall R, Mellin-Olsen J, Enright A. The COVID-19 pandemic: effects on low- and middle-income countries. Anesth Analg. 2020;131:86-92.

47. National Institue of Health $\mathrm{NIH}$. Coronavirus disease 2019 (COVID-19) treatment guidelines; 2020. https://files.covid19treatmentguidelines. nih.gov/guidelines/covid19treatmentguidelines.pdf

48. Shrestha R, Prajapati S. Assessment of prescription pattern and prescription error in outpatient Department at tertiary care district hospital, Central Nepal. J Pharm Policy Pract. 2019;12:16.

49. Chin TW, Chant C, Tanzini R, Wells J. Severe acute respiratory syndrome (SARS): the pharmacist's role. Pharmacotherapy. 2004;24:705-712.

50. European Centre for Disease Prevention and Control. Infection Prevention and Control and Preparedness for COVID-19 in Healthcare Settings; 2020. Accessed April 29, 2020. https://www.ecdc.europa.eu/ sites/default/files/documents/nove-coronavirus-infection-preventioncontrol-patients-healthcare-settings.pdf

51. Sakeena MHF, Bennett AA, McLachlan AJ. Enhancing pharmacists role in developing countries to overcome the challenge of antimicrobial resistance: a narrative review. Antimicrob Resist Infect Control. 2018;7:63.

52. Koehler T, Brown A. A global picture of pharmacy technician and other pharmacy support workforce cadres. Res Soc Adm Pharm. 2017;13:271279.

53. Alipour F, Peiravian F, Mehralian G. Perceptions, experiences and expectations of physicians regarding the role of pharmacists in lowincome and middle-income countries: the case of Tehran hospital settings. BMJ Open. 2018;8:e019237.

54. Babar Z, Scahill S. Barriers to effective pharmacy practice in low-and middle-income countries. Integr Pharm Res Pract. 2014;52:25-27.

55. Shrestha S, Kandel P, Danekhu K, Bhuvan KC. Reflecting on the role of a pharmacist during the two major earthquakes of 2015: are we prepared for similar future disasters? Res Soc Adm Pharm. 2019;15:1500-1501.

56. Hannings AN, von Waldner T, McEwen DW, White CA. Assessment of emergency preparedness modules in introductory pharmacy practice experiences. Am J Pharm Educ. 2016;80:23.

57. Porter KE, Singleton JA, Tippett V, Nissen LM. Ready, willing and able: the role of pharmacists in natural and manmade disasters - can we do more? Int J Pharm Pract. 2018;26:195-196. 